\title{
Practical Teaching Method Based on Integration of Science and Engineering
}

\author{
Gao Yan ${ }^{1, \mathrm{a}^{*}}$, Chen Qing ${ }^{1}$, Wu Zhiyi ${ }^{1}$, Li Wenlong ${ }^{1}$, Zhou Yibin ${ }^{1}$ \\ ${ }^{1}$ School of Earth Sciences and Engineering, Sun Yat-sen University, Zhuhai, Guangdong, China \\ a*gaoyan25@mail.sysu.edu.cn
}

\begin{abstract}
The integration of science and engineering and the collaborative innovation aim to establish a teaching model characterized by the problem orientation, which can be achieved through practical training projects. Through the construction of students' collaborative innovation team and teachers' collaborative innovation guidance team, the collaborative innovation platform is built up and further sheared to more students. Taking the construction of students' collaborative innovation practice team as the core, assisted by the construction of teachers' collaborative innovation guidance team, it aims to establish a collaborative innovation platform in which students are the main body and can use of knowledge of science and engineering flexibly. Based on the professional characteristics and rich teaching practice experience of geology and geological engineering in the college, through three on-site teaching practices, bringing into full play to students' subjective initiative, the source of innovation and scientific research can be burst out fully.
\end{abstract}

Keywords: New engineering training, integration of science and engineering, synergistic innovation, practical teaching.

\section{基于理工科交叉融合的实践教学方法}

\author{
高燕 ${ }^{1, \text { a* }}$ ，陈庆 ${ }^{1}$ ，武志毅 ${ }^{1}$ ，李文龙 ${ }^{1}$ ，周羿彬 ${ }^{1}$ \\ ${ }^{1}$ 中山大学地球学科与工程学院, 广东珠海, 中国 \\ a*gaoyan25@mail.sysu.edu.cn
}

\section{摘要}

理工科思维与协同创新的相辅相成旨在建立以问题导向为主要特征的教学模式, 通过实训项目, 完成协同创新 工作实践。通过学生协同创新团队建设、教师协同创新指导团队建设，完成协同创新试验平台搭建以及协同创 新平台共享。其中以学生协同创新实践团队建设为核心, 教师协同创新指导团队建设和协同创新试验平台搭建 为辅助, 旨在建立以 “理工科思维并重” 学生为主体的协同创新平台。基于学院地质学与地质工程专业的专业 特色与丰富的教学实践经验, 通过三次现场教学实践, 充分发挥学生协同创新实践团队的主观能动性, 让一切 有助于创新与科研的源泉充分迸发, 取得良好效果。 关键词: 新工科, 理工科交叉融合, 协同创新, 实践教学

\section{1. 前言}

高校工科教育是实践和理论并重的专业教育, 实 践教学亦是高等教育工科教学的重要组成部分。随着 社会经济的发展和社会企业对工科人才的需求, 新时 代的高素质人才应具有洲博的工科基础理论知识, 较 强的实践应用能力, 较强的创新意识以及创新能力。 然而长久以来, 我国的工科教育实践环节一直是较薄
弱环节。为培养高素质的新型创新人才，依托学院现 有的地质学、地球物理及地质工程的学科各自优势, 打造多学科交叉的紧密结合点, 搭建理科与工科交叉 融合的培养方式, 是培养综合性人才的重要尝试, 是 新工科的体现。为了实现学科的交叉融合的高效化, 需要制定科学合理的教学大纲、选课体系、教学方法 等教学环节, 实践教学是重要的环节。 
从地质工程专业考虑, 实践教学可以将有关地质 的理论知识与地质风险防治、地质现象解释完美结合, 探讨理科与工科交叉融合, 增加学生的兴趣爱好, 培 养学生的团队协作能力, 提高学生的实践应用能力和 创新意识, 亦坚定了对党和国家的热爱。

\section{2. 理工科思维与协同创新平台搭建}

基于学院地质学与地质工程专业丰富的教学实 践经验, 组建具备理工科思维教学能力、解决理工科 实践问题的教师协同创新指导团队; 在学生内部组建
4-5 人一组的具有理学、工学专业背景的学生协同创 新实践团队。以实践项目为实训, 建立以问题导向为 主要特征的学习模式。组建具有理工科专业背景的跨 专业师生协同创新团队以及专业实验人员团队，教师 协同创新指导团队发挥技术支撑与研究指导的作用, 培养学生的理工科思维并重的创新意识; 专业实验人 员团队指导、协助学生开展工作，充分发挥学生协同 创新实践团队的主观能动性, 力图让创新的种子充分 萌发、让创新的源泉充分涌流。协调创新平台搭建示 意图如图 1 所示。

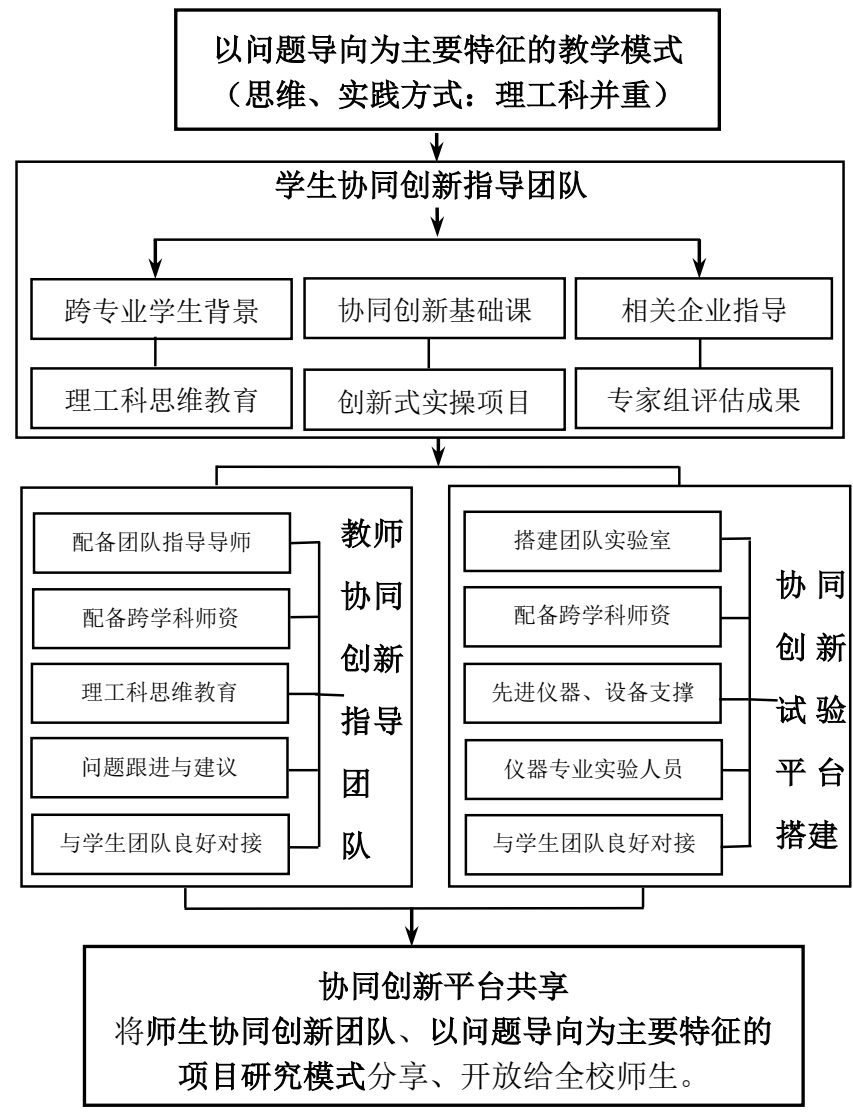

图 1 协同创新平台搭建示意图

\section{3. 实践教学}

为了探究适合理工科交叉融合的协调创新的教 学模式, 依托广东省的地貌、典型城市的灾害特征与 发展模式, 通过实践教学方法, 针对性地组织了三次 实践活动, 分别是连州一清远岩溶地貌、深圳市地质 灾害及防治与深圳 CBD 发展模式。

\section{1. 实践教学 1-连州清远岩溶地貌}

广东省属于亚热带季风气候, 年平均气温为 $22^{\circ} \mathrm{C}$, 年降雨量丰富但时间分布不均。广东省区域内岩浆活 动频繁而强烈, 分布面积约占陆地面积的 $40 \%$, 侵入 岩以花岗岩类为主, 并有少量镁铁质、超镁铁质岩及 碱性岩 ${ }^{[1]}$ 。通过对区内构造特征的认识 ${ }^{[2-5]}$, 针对区域
内的岩溶发育情况的提前调研、现场勘测、思维发散, 从理论到实际, 展现实践教学的优势。由于区内发育 的碳酸盐岩、丰富的降水以及定向性较好的褶皱及断 层, 使得连州一清远研究区岩溶现象十分发育, 地表 多形成溶沟、石林、石芽等; 地下形态多形成裂隙、 暗河、溶洞、石笋等。

连州地下河上下共分三层, 全长 1860 米, 最高 处 47.8 米, 最宽处 53.6 米, 可供游览面积达 6 万平 方米。洞内四季气温常年保持在 $18^{\circ} \mathrm{C}$ 左右, 湿度 $96 \%$ $98 \%$, 空气新鲜, 冬暖夏凉。地下暗河位于下层, 水 流由北向南, 蜿蜒曲折十八弯, 经过三个美丽的峡谷: 龙门峡、莲花峡、香蕉峡, 全长 1500 米。沿河两岸 和陆地第二层和第三层布满石钟乳、石英、石柱、石 花、石幔等，如图 2 所示。 
(a)

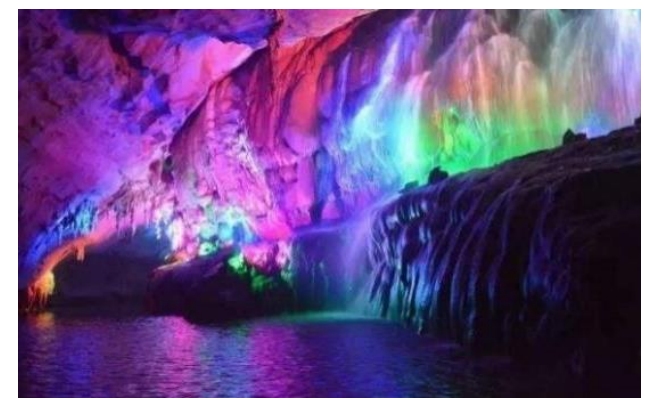

(b)

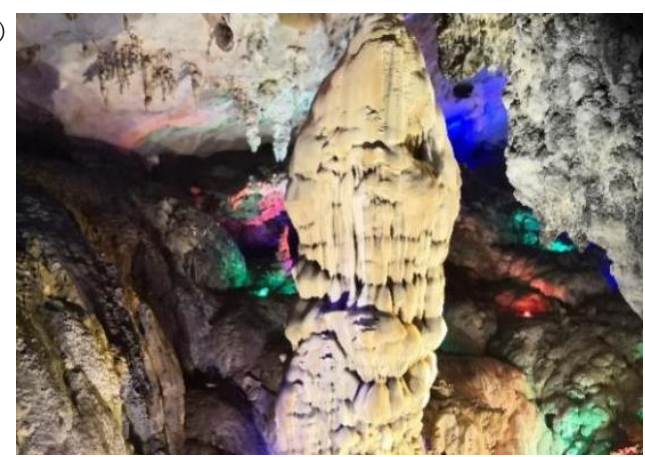

图 2 连州地下河:（a）地下暗河;（b）石柱

清远天坑被称为华南第一坑, 以其独特的喀斯特 地貌、沟壑险峻的地理特征为依托，融山、水、石、 潭、钟乳、瀑布、天桥、天坑、绿洲为一体。洞天仙 境, 溪流穿山而过的岩洞, 洞口垂吊一个巨大的钟乳 石, 洞内广阔, 钟乳石形态多样, 洞顶有 2 个穿孔通 天, 光线从中透入洞里。图 3 的岩溶蜂窝状孔洞十分 典型, 只分布在阳光可直射的一侧, 推测是由于水蚀 和风蚀的共同作用, 在原始的岩石微裂隙中大量发育, 由于阳光直射, 使得侵蚀作用强烈, 形成典型的蜂窝 状孔洞。

(a)

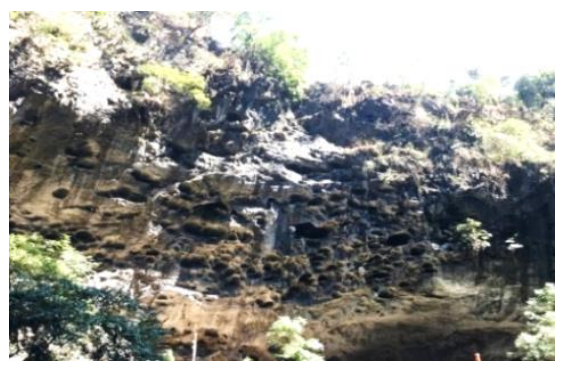

(b)

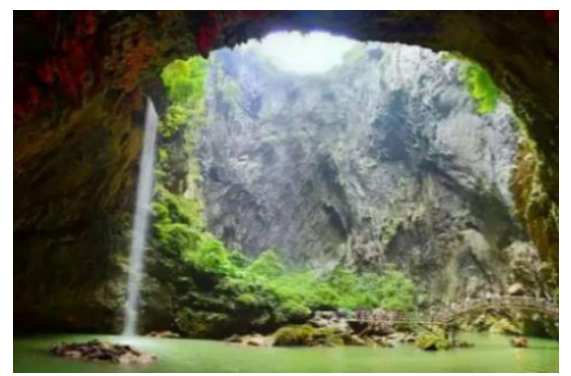

图 3 清远天坑:（a）蜂窝状岩石;（b）天坑

现场的调研促使学生探索自然的奥秘, 加深实际 与专业的联系。除了岩溶地貌, 其所能引起的地质灾 害也不容忽视, 引导学生用辩证方法看待问题的思维,
引导学生思考工程问题。岩溶地基一般采用换填、灌 浆等处理手段, 若前期岩土工程勘察中没有发现土洞, 可引起地基土体变形、建筑物开裂坉塌。因此对于岩 溶塌陷的监测与治理就显得尤为重要。对岩溶塌陷的 监测不仅有助于提高工程设计合理性并优化方案, 还 能够保障工程的施工质量与安全, 提高经济效益。此 外, 全面的监测还能够及时发现和预报工程施工过程 中的异常情况, 防止工程事故, 保障工程的施工安全, 对指导工程实践具有重要的意义。

\section{2. 实践教学 2-深圳市主要地质灾害及防治 措施}

引导学生从灾害现象到致灾机理与防治的系统 性认识。深圳市位于广东省南部, 地处北回归线以南。 斜坡类地质灾害是深圳市最主要的地质灾害类型, 主 要分布在宝安区的东北部的石岩街道地区、东南部地 区的西乡街道, 光明新区南部的光明街道地区, 龙岗 南部的布吉街道、南湾街道地区, 罗湖区的莲塘街道 地区, 盐田的海山街道、梅沙街道地区, 大鹏新区南 澳街道的新屋村地区等, 分布广泛, 危害性大。崩塌 隐患点主要分布在深圳市南山区桃源街道新屋村、招 商街道、桃源街道地区, 福田区的梅林街道地区, 罗 湖区的莲塘街道地区, 盐田区的沙头角街道地区 ${ }^{[6]}$ 。

根据灾害规模分级，可将滑坡分为小型、中型、 大型、巨型四个等级, 将崩塌点分为微型、小型、中 型、大型四个等级。其中，深圳市滑坡规模以小型为 主，占滑坡总数的 $92.1 \%$ 。崩塌规模以微型为主，占 崩塌点总数的 $69.8 \%$ 。其具体占比如图 4、5 所示。滑 坡和崩塌具有空间和时间分布特征，其空间分布特征 体现在两方面: 1) 灾害的分布与高程的关系, 滑坡大 部分分布在 $40-80 \mathrm{~m}$ 的高程范围内, 占总数的 $69.4 \%$, 崩塌大部分分布在 $20-40 \mathrm{~m}$ 的高程范围内, 占总数的 $67.3 \%$ 。2) 灾害的分布与坡度的关系, 深圳滑坡多 发生在 $40^{\circ}-70^{\circ}$ 的斜坡, 占总数的 $94.2 \%$, 崩 塌多发生在 $50^{\circ}-80^{\circ}$ 的斜坡，占总数的 $73.8 \%$ 。其时 间分布特征具同时性和滞后性两种规律。深圳每年 49 月为雨季, 降雨量占年降雨量的 $84 \%$ 。据统计, $92.6 \%$ 的崩塌、滑坡灾害发生于这一时段[7]。

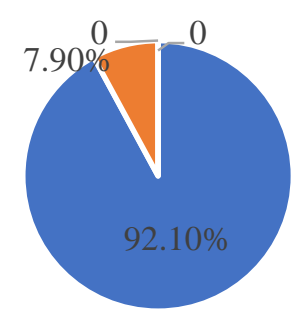

・ 小型・中型 "大型 “巨型

图 4 深圳市滑坡规模分级 


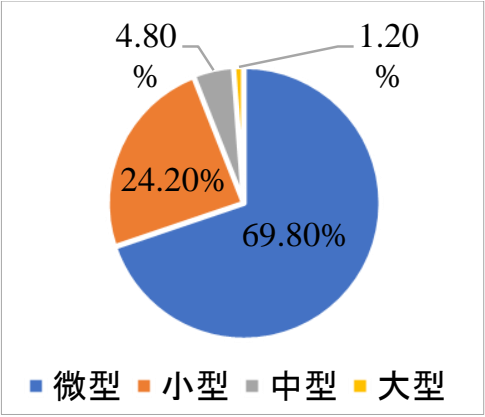

图 5 深圳市崩塌规模分级

造成地质灾害的原因主要有地质构造、地层岩性、 水文地质条件、气候与人为因素。经调研, 深圳市常 见针对滑坡的防治主要采取挡土墙、抗滑桩、防护网、 针索等抗滑工程, 加上排水、削方、生物治理等手段 降低滑坡发生的可能 (如图 6 所示)。另外还需加强 地质灾害调查与研究工作，应用先进的监测技术，创 建地质灾害预警预报系统, 地质灾害治理与美化城市 环境相结合, 提高地质灾害防治的勘察设计和管理水 平 ${ }^{[8]}$ 。

(a)

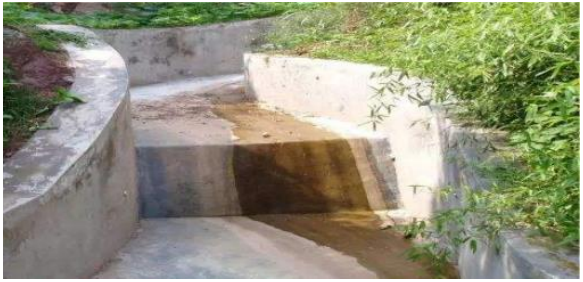

(b)

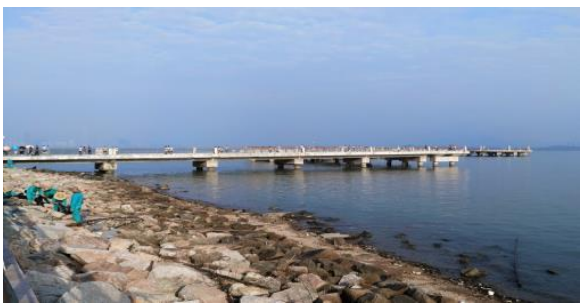

(c)

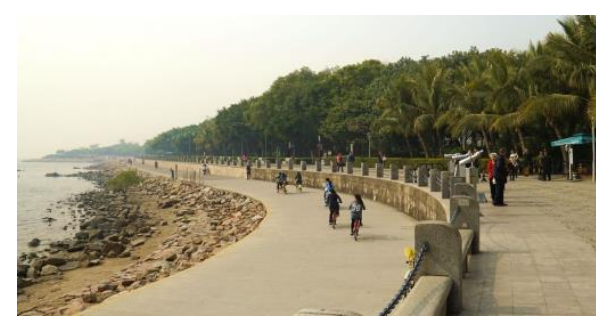

(d)

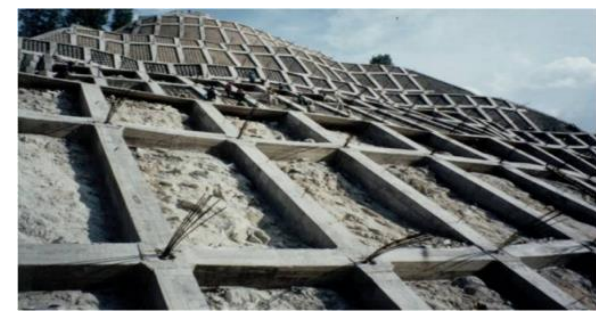

图 6 深圳市常见滑坡防护:（a）排水沟;（b）海岸 挡土墙; (c) 生物防治 (红树林); (d) 预应力针索

\section{3. 实践教学 3-深圳 $C B D$ 发展模式}

\section{3. 1. 深圳 $C B D$ 发展模式}

中心商务区 (CBD, Central Business District) 是 一个城市的核心部分，是城市的心脏，是城市综合性 经济活动的中枢。深圳的 CBD 发展模式呈现出向西 转移的发展特点, 表现在城市中心的职能转移 ${ }^{[9]}$, 房 地产市场的趋势等。学生通过深入实践调研, 分析出 深圳 CBD 西移的驱动力主要有以下几个方面:

1)中心区西移的内在动力:城市经济重心向西转 移, 是深圳 CBD 西移的根本因素。

2)罗湖的限制:房地产市场供给失衡。

3)皇岗口岸的建设:便利的出关与交通条件。

4)市政府的西迁:带动房地产业发展的重要推力。

5)政府的努力推动:福田中心区成长的动力。

\section{3. 2. 深圳 $C B D$ 前景展望}

通过实践调研, 学生深入理解了深圳新一轮城市 总体规划, 亦培养了爱国主义情怀。深圳将建立三级 城市中心体系, 以福田中心和前海中心为 2 个城市中 心开展建设。福田中心包括福田中心区、罗湖中心区, 主要发展市级行政、文化、商业、商务等职能。前海 中心, 包括前海、后海和宝安中心区, 主要发展区域 功能的生产性服务业与总部经济。而对南山区的建设 将以世界一流湾区为标杆, 发挥南山在粤港澳大湾区 独特的区位优势, 串联深圳湾、后海金融商务总部基 地、前海蛇口自贸片区, 打造滨海总部经济带, 吸引 国际资本集聚，建设具特区风格的粤港澳大湾区城市 群“新地标”[10, 11]。

\section{4. 结论}

通过三次实践教学, 学生充分认识到理论和实践 结合的重要性, 拓宽学生的知识面, 提高学生的就业 能力, 亦增加了学生的爱国主义情怀。充分发挥学生 的主观能动性, 将专业知识和实践相结合, 锻炼了实 践应用能力和综合知识运用能力, 全面提升了自身的 团队合作意识、科研素质和创新意识。在实践教学中, 增加实践环节的多样性, 提高学生专业素质, 在理科 与工科交叉融合人才培养方案设置中提高实践教学 比例, 细化实践教学考核标准, 提高教学的科学性。

\section{REFERENCES}

[1] Shu L.S. (2012) An analysis of principal features of tectonic evolution in South China Block. Geological Bulletin of China, 31(07):1035-1053.

[2] Yan Z.W. (2006) Karst hydrogeological features research in Yuantou underground river system. Water Conservancy Science and Technology and 
Economy. 12(11):741-747.

[3] Jia L. (2017) Determination and significance of nappe structure in Lianzhou area of Guangdong. Westem Resources, 03:59-61.

[4] Huang Y. J. (2010) Study on Ground Treatment and Foundation Selection in Karst District of Lianzhou. South China University of Technology.

[5] Zhang G.W., Guo A. L., Wang Y. J., Li S.Z., Dong Y. P., Liu S. F., He D. F., Cheng S. F., Lu R. K., Yao A.P. (2013) Tectonics of South China continent and its implications. Scientia Sinica(Terrae), 43(10):1553-1582.

[6] Tang R. (2016) Analysis of hidden dangers from geological hazards, and safety recommendations. Shanghai Land \& Resources, 37(03):82-85.

[7] Xiong J.A., Wang L. (2013) Characteristics and causes of slope geo-hazards in Shenzhen. Journal of Geological Hazards and Environment Preservation, 24(03):70-75.

[8] Li L.G., Xu Y.S., Jiang H.H., Liu X.P. (2007) Characters of Geological Environment and the Precaution of Geological Hazards in Shenzhen Area. Safety and Environmental Engineering, 04:28-31.

[9] Wang R.Y., Li Y.R. (2002) The mechanism of the westwardly changing of the Shenzhen central business district (CBD). Economic Geography, 02:165-169.

[10] Jiang Y.J. (2011) The current situation and development strategy of Shenzhen CBD. Practice and Theory of SEZS, 04:81-83.

[11] Li Z. G. (2004) Central "blessed land" rises in Shenzhen CBD. https://wap.cnki.net/baozhiJJRB200410130132.html. 